\title{
Effect of Crosslinkers on Optical and Mechanical Behavior of Chiral Nematic Liquid Crystal Elastomers
}

\author{
Kyosun Ku ${ }^{1}$, Kyohei Hisano ${ }^{1}{ }^{\mathbb{D}}$, Kyoko Yuasa ${ }^{1}$, Tomoki Shigeyama ${ }^{1}$, Norihisa Akamatsu ${ }^{2}$, Atsushi Shishido ${ }^{2}$ \\ and Osamu Tsutsumi ${ }^{1, *(1)}$ \\ 1 Department of Applied Chemistry, Ritsumeikan University, 1-1-1 Nojihigashi, Kusatsu 525-8577, Japan; \\ gr0343xf@ed.ritsumei.ac.jp (K.K.); hisano@fc.ritsumei.ac.jp (K.H.); sc0065if@ed.ritsumei.ac.jp (K.Y.); \\ sc0060kf@ed.ritsumei.ac.jp (T.S.) \\ 2 Laboratory for Chemistry and Life Science, Tokyo Institute of Technology, 4259 Nagatsuta, Midori-ku, \\ Yokohama 226-8503, Japan; akamatsu@res.titech.ac.jp (N.A.); ashishid@res.titech.ac.jp (A.S.) \\ * Correspondence: tsutsumi@sk.ritsumei.ac.jp; Tel.: +81-77-561-5966
}

Citation: Ku, K.; Hisano, K.; Yuasa, K.; Shigeyama, T.; Akamatsu, N.; Shishido, A.; Tsutsumi, O. Effect of Crosslinkers on Optical and Mechanical Behavior of Chiral Nematic Liquid Crystal Elastomers Molecules 2021, 26, 6193. https:// doi.org/10.3390/molecules26206193

Academic Editor: Haifeng Yu

Received: 6 September 2021

Accepted: 10 October 2021

Published: 14 October 202

Publisher's Note: MDPI stays neutra with regard to jurisdictional claims in published maps and institutional affiliations.

Copyright: (c) 2021 by the authors. Licensee MDPI, Basel, Switzerland. This article is an open access article distributed under the terms and conditions of the Creative Commons Attribution (CC BY) license (https:// creativecommons.org/licenses/by/ $4.0 /)$.

\begin{abstract}
Chiral nematic $\left(\mathrm{N}^{*}\right)$ liquid crystal elastomers (LCEs) are suitable for fabricating stimuliresponsive materials. As crosslinkers considerably affect the $\mathrm{N}^{*} \mathrm{LCE}$ network, we investigated the effects of crosslinking units on the physical properties of $N^{*} L C E s$. The $N^{*} L C E s$ were synthesized with different types of crosslinkers, and the relationship between the $\mathrm{N}^{*} \mathrm{LC}$ polymeric system and the crosslinking unit was investigated. The $\mathrm{N}^{*} \mathrm{LCEs}$ emit color by selective reflection, in which the color changes in response to mechanical deformation. The LC-type crosslinker decreases the helical twisting power of the $\mathrm{N}^{*} \mathrm{LCE}$ by increasing the total molar ratio of the mesogenic compound. The $N^{*}$ LCE exhibits mechano-responsive color changes by coupling the $\mathrm{N}^{*} \mathrm{LC}$ orientation and the polymer network, where the $\mathrm{N}^{*} \mathrm{LCEs}$ exhibit different degrees of pitch variation depending on the crosslinker. Moreover, the LC-type crosslinker increases the Young's modulus of $\mathrm{N}^{*} \mathrm{LCEs}$, and the long methylene chains increase the breaking strain. An analysis of experimental results verified the effect of the crosslinkers, providing a design rationale for $\mathrm{N}^{*} \mathrm{LCE}$ materials in mechano-optical sensor applications.
\end{abstract}

Keywords: crosslinkers; chiral nematic liquid crystal elastomer; selective reflection; mechanooptical sensor

\section{Introduction}

Chiral nematic $\left(\mathrm{N}^{*}\right)$ liquid crystals (LCs) have attracted considerable scientific attention because of their fascinating optical properties that arise from the helical orientation of LC molecules in the nanoscale to microscale range [1-3]. The periodic helical structure of an $N^{*}$ LC spontaneously self-assembles when an achiral LC is mixed with chiral moieties and/or a chiral LC is used [4,5]. This helix has a refractive-index distribution along the helical axis and exhibits selective reflection of circularly polarized light with the same handedness at a specific wavelength according to Bragg reflection [6,7]. The peak reflection wavelength $\left(\lambda_{\text {peak }}\right)$ is related to the helical pitch $(P)$ corresponding to the length of a $2 \pi$ molecular rotation: $\lambda_{\text {peak }}=n_{\text {ave }} \cdot P \cdot \sin \theta$, where $n_{\text {ave }}$ is the average refractive index of ordinary $\left(n_{0}\right)$ and extraordinary $\left(n_{\mathrm{e}}\right)$ refractive indices of the medium, and $\theta$ is the incident angle of the light [8,9]. Such optical properties enable the development of a wide range of $\mathrm{N}^{*}$ LC-based optical applications in fields such as lasers [10], security inks [11], reflective displays [12,13], and sensors [14].

Crosslinked $\mathrm{N}^{*} \mathrm{LC}$ polymers are increasingly used for developing stimuli-sensitive devices [15]. Crosslinking the $\mathrm{N}^{*} \mathrm{LC}$ polymer network can stabilize the helical molecular orientation. Under external stimuli, the molecular orientation and corresponding material properties change, and when the stimuli are removed, the original molecular orientation is recovered [16-18]. Crosslinked $N^{*}$ LC polymer networks are classified by crosslinking 
density into densely crosslinked LC networks (LCNs) or loosely crosslinked LC elastomers (LCEs); in particular, the LCEs swelled by low-molecular-weight LCs are termed LC gels [19]. Due to the dense crosslinking, LCNs are environmentally stable, but their stimuli responsivity is quite low $[20,21]$. In contrast, LCEs show higher sensitivity and reversibility under external stimuli, which are favorable for stimuli-responsive applications [22,23]. In particular, the $\mathrm{N}^{*} \mathrm{LCE}$ enables selective reflection, where $\lambda_{\text {peak }}$ changes under external stimuli. Thus, $\mathrm{N}^{*}$ LCEs are key components for developing electro-, thermo-, or mechanoresponsive optical sensors with excellent repeatability and sensitivity [24-28].

Such $N^{*}$ LCEs have been widely synthesized using various polymerization systems and chemical components [29-32]. Previous studies suggest that crosslinking units affect the physical properties of $\mathrm{N}^{*} \mathrm{LCEs}$, including their phase transition behavior, thermal stability, optical properties, and mechanical properties. Once crosslinking units are optimized for desired optical properties, other materials' properties may be deteriorated [33-35]. In particular, the relationship between crosslinkers in chemical systems and the resultant optical properties arising from the ability of chiral dopants to generate helical molecular orientations, i.e., the helical twisting power (HTP), has rarely been examined. Typically, HTP is expressed as follows: HTP $=(P \cdot c)^{-1}$, where $c$ is the molar fraction of the chiral dopant [36]. Although HTP is important for designing the selective reflection color, it depends on the chemical system used, and the concentration of the active components must be optimized in each system. Therefore, a good understanding of the relationship between the crosslinker structure and HTP is necessary for providing us with a synthetic strategy for the creation of both $\mathrm{N}^{*}$ LCEs and other materials with desired optical properties.

In this study, to investigate the effect of crosslinking units in $N^{*} \mathrm{LCE}$ materials on both optical and mechanical properties, we synthesized $\mathrm{N} *$ LCEs with various crosslinkers: flexible methylene chains with different lengths and/or mesogenic units. The resultant $\mathrm{N}^{*}$ LCEs showed mechano-responsive reflection color changes under applied tensile strain, indicating that the proposed system is applicable to mechano-optical sensors. Similar shifts in $\lambda_{\text {peak }}$ under strain were observed, irrespective of whether the crosslinkers had mesogenic units. Furthermore, the thermal, optical, and physical properties of the $\mathrm{N}^{*} \mathrm{LCEs}$ were characterized. Increasing the length of the methylene chains had almost no effect on the thermal and optical properties of the resultant $\mathrm{N}^{*}$ LCEs. In chemical systems using a non-mesogenic crosslinker, the HTP of the chiral agent was consistent with previously reported values [37]; in particular, the system with a mesogenic crosslinker had a smaller HTP value than those without mesogenic units, meaning that the optical property differed from the expected one. Our results revealed that the low HTP value in the mesogenic crosslinker system is due to the larger molar ratio of mesogenic compounds (the sum of the LC monomer and mesogenic crosslinker). Thus, by setting the molar ratio of the chiral agent to that of all mesogenic compounds, the HTP became equal to that of the non-mesogenic crosslinking system. This strategy enables mechano-optical sensors to be designed with a desired initial color by tailoring the relative amounts of chiral agents, while the other material properties can be tuned by changing the crosslinkers.

\section{Results and Discussion}

\subsection{Phase Transition Behavior}

Structures of monomeric materials used for preparation of the $\mathrm{N}^{*} \mathrm{LCEs}$ are shown in Scheme 1. The phase transition temperatures of the monomer mixtures and $\mathrm{N}^{*} \mathrm{LCEs}$ are summarized in Table 1. As shown in Figure 1, polarized optical microscopy (POM) observations revealed that at the $\mathrm{LC}$ temperature, the monomer mixtures exhibit a Grandjean texture, which is typically observed for the homogenous helical molecular orientation in the $\mathrm{N}^{*} \mathrm{LC}$ phase. The $\mathrm{N}^{*} \mathrm{LC}$-to-isotropic phase transition temperature (clearing point, $T_{\mathrm{c}}$ ) and crystalline-to- $\mathrm{N}^{*} \mathrm{LC}$ phase transition temperature (melting point, $T_{\mathrm{m}}$ ) of the monomer mixtures were slightly decreased by increasing the methylene chain length in the crosslinking unit. This demonstrates that increasing the methylene chain length in the crosslinking units contributes to destabilizing the LC phase by increasing the volume of non-LC units. 
Generally, non-LC-type molecules destabilize the LC phase by disturbing the formation of the LC molecular arrangement [38]. In contrast, $T_{\mathrm{c}}$ and $T_{\mathrm{m}}$ of the monomer mixture with a mesogenic crosslinker, RM82, were observed at $53{ }^{\circ} \mathrm{C}$ and $22{ }^{\circ} \mathrm{C}$, respectively. These results indicate that RM82 contributes to the stabilization of the LC phase.
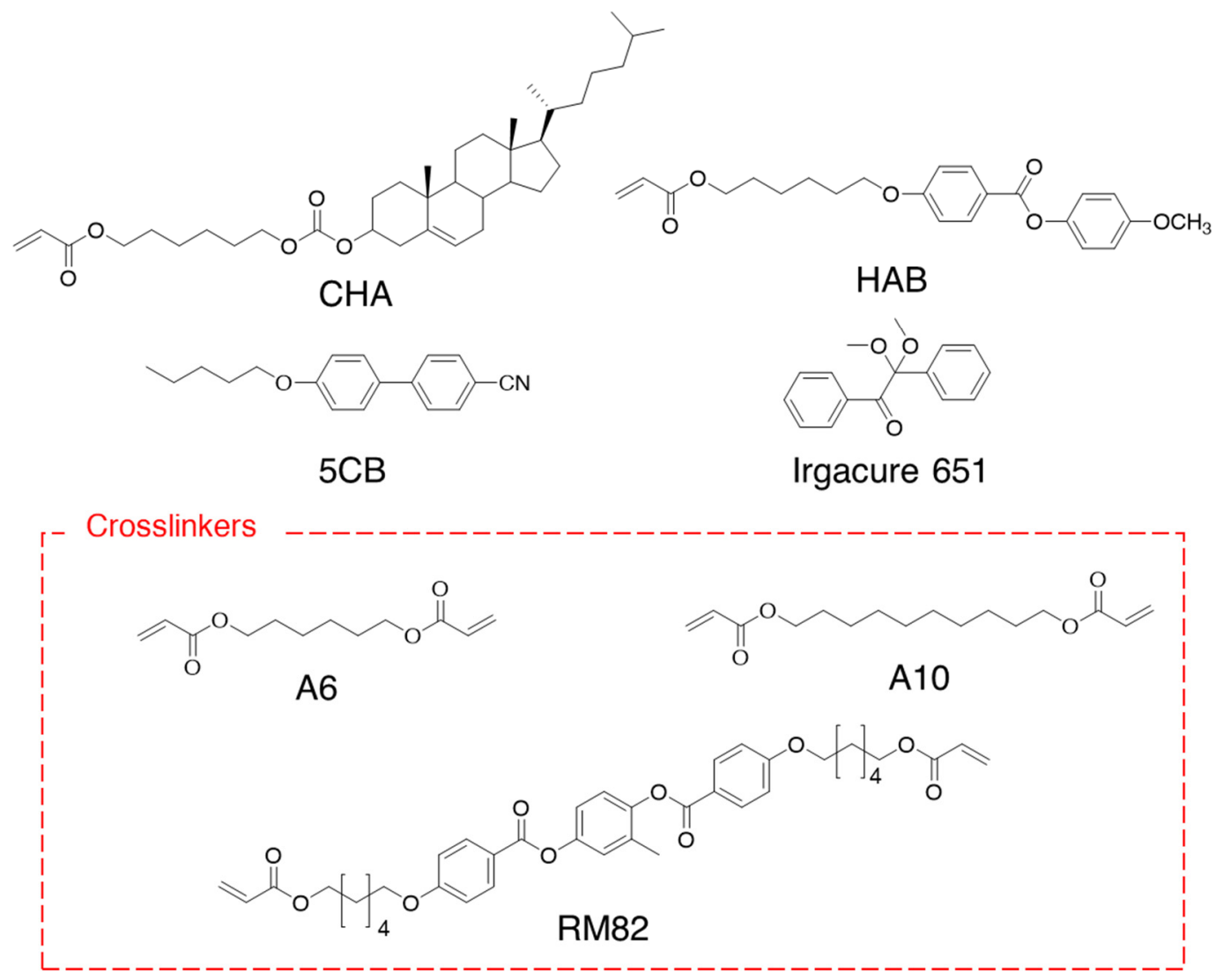

Scheme 1. Chemical structures of the compounds used in the synthesis of $\mathrm{N}^{*}$ LCEs.

Table 1. Phase transition temperatures of monomer mixtures and $\mathrm{N}^{*} \mathrm{LCEs}$ with different crosslinkers.

\begin{tabular}{c|cc}
\hline \multirow{2}{*}{ Crosslinker } & \multicolumn{2}{|c}{ Phase Transition Temperature ${ }^{a}\left({ }^{\circ} \mathrm{C}\right)$} \\
\cline { 2 - 3 } & Monomer Mixture & $\mathbf{N}^{*} \mathrm{LCE}$ \\
\hline A6 & $\mathrm{C} 22 \mathrm{~N}^{*} 31 \mathrm{I}$ & $\mathrm{G} 0 \mathrm{~N}^{*} 82 \mathrm{I}$ \\
A10 & $\mathrm{C} 12 \mathrm{~N}^{*} 26 \mathrm{I}$ & $\mathrm{G} 2 \mathrm{~N}^{*} 84 \mathrm{I}$ \\
RM82 & $\mathrm{C} 22 \mathrm{~N}^{*} 53 \mathrm{I}$ & $\mathrm{G} 11 \mathrm{~N}^{*} 100 \mathrm{I}$ \\
\hline
\end{tabular}

${ }^{a}$ Phase transition temperature of compounds; C, crystal; G, glass; $\mathrm{N}^{*}$, chiral nematic; I, isotropic.

The phase transition temperatures were determined by POM (Figure 1) for the monomer mixture and by differential scanning calorimetry (DSC) for $\mathrm{N}^{*} \mathrm{LCE}$ in the 2nd cooling process (Figure 2).

After photopolymerization of the mixtures, we obtained an $\mathrm{N}^{*} \mathrm{LC}$ polymeric film with a Grandjean texture, as shown in Figure 1. The films exhibited a reversible phase transition from $\mathrm{N}^{*} \mathrm{LCs}$ to isotropic phases with increasing temperature, and vise versa. The DSC curves indicated the glass transition temperature $\left(T_{\mathrm{g}}\right)$ and $T_{\mathrm{C}}$ of the films, as shown in Figure 2. Although the $T_{\mathrm{g}}$ of the resultant films was slightly different depending on the chemical structure of the crosslinkers, they all showed a $T_{\mathrm{g}}$ below room temperature $\left(\sim 25^{\circ} \mathrm{C}\right)$. Therefore, all the resultant polymers serve as elastomers at room temperature. Considering that typical acrylic polymers show a $T_{\mathrm{g}}$ of $\sim 40^{\circ} \mathrm{C}$, the $T_{\mathrm{g}}$ of the reported $\mathrm{N}^{*} \mathrm{LCEs}$ is quite low. This is due to the use of $5 \mathrm{CB}$, a low-molecular-weight, roomtemperature LC, which swells the polymer network to serve as a plasticizer and activates the micro-Brownian motion. The $T_{\mathrm{c}}$ values of E-A6 and E-A10 were similar, $82{ }^{\circ} \mathrm{C}$ and 
$84^{\circ} \mathrm{C}$, respectively. E-RM82 showed a higher $T_{\mathrm{C}}$ than E-A6 or E-A10. This demonstrates that the $\pi$-conjugation of the aromatic ring in the RM82 unit increased $T_{\mathrm{C}}$ by increasing molecular order and rigidity $[39,40]$. Therefore, $\mathrm{N}^{*} \mathrm{LCEs}$ with a gel system can function as elastomers, irrespective of the chemical structure of the crosslinkers, where the stability of the $N^{*}$ LC phase can be increased using a mesogenic crosslinker. The results exhibit that the phase transition temperature is controlled by a crosslinker and provides high thermal stability in $\mathrm{N}^{*} \mathrm{LCE}$. The high thermal stability of the $\mathrm{N}^{*} \mathrm{LC}$ phase extends the range of actuation temperature and allows various application fields in extreme environmental fields as a mechano-optical sensor.

(a)

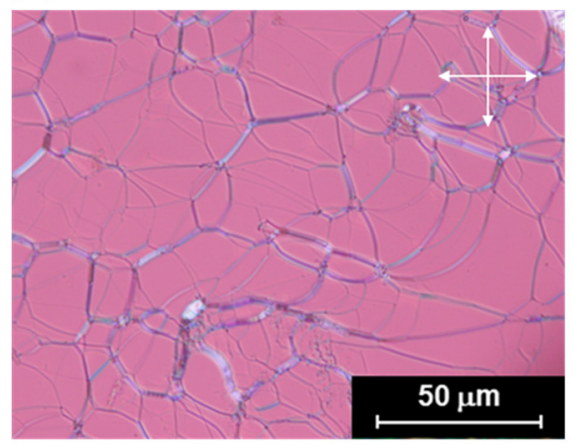

(c)

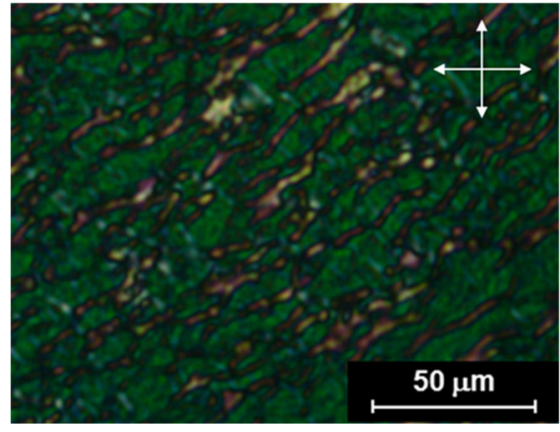

(b)

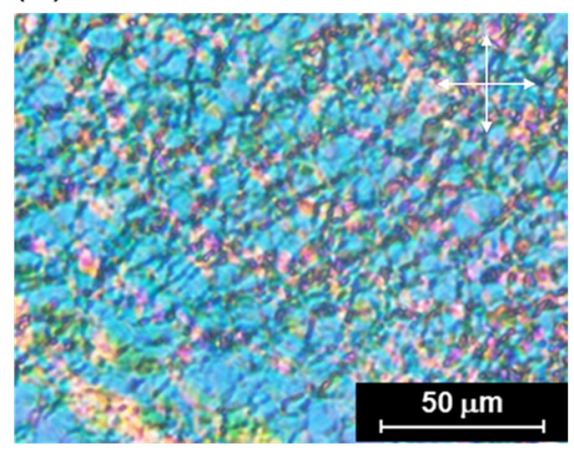

(d)

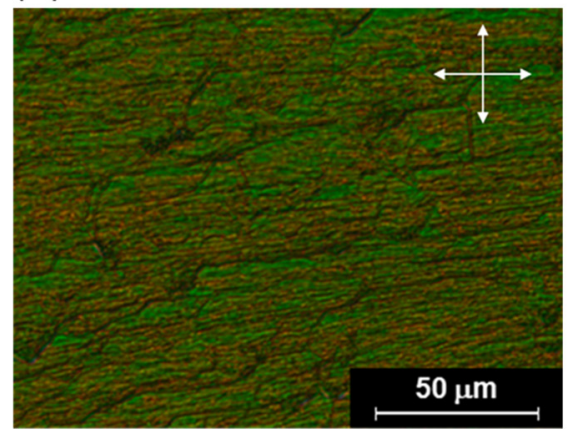

Figure 1. POM images of $\mathrm{N}^{*} \mathrm{LC}$ samples before and after photopolymerization: (a) E-A6 before photopolymerization (as a representative example); (b) E-A6 after photopolymerization; (c) E-A10 after photopolymerization; (d) E-RM82 after photopolymerization.

(a)

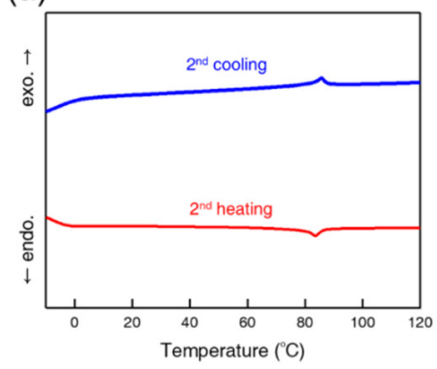

(b)

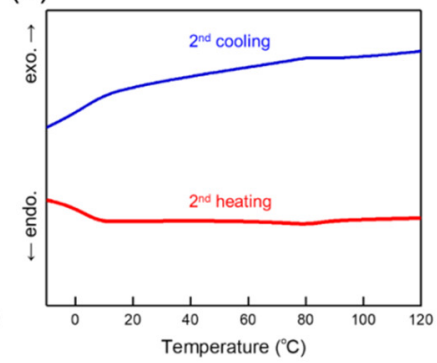

(c)

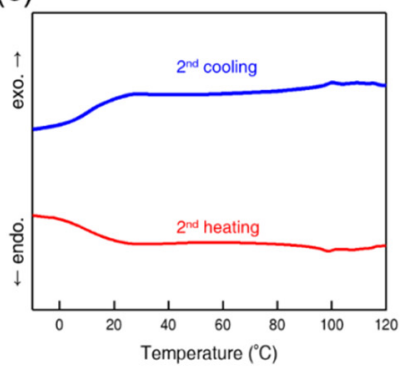

Figure 2. DSC thermograms of $\mathrm{N}^{*} \mathrm{LCEs}$ on the second scanning cycles from $-10{ }^{\circ} \mathrm{C}$ to $120{ }^{\circ} \mathrm{C}$ : (a) E-A6, (b) E-A10, and (c) E-RM82. The scanning rate was $10{ }^{\circ} \mathrm{C} \mathrm{min}^{-1}$.

\subsection{Optical Properties of $N^{*} L C E S$}

The E-A6 and E-A10 had a bright bluish-green color, while E-RM82 appeared orange (Figure $3 a$ ). Figure $3 b$ shows the reflectance spectra of the $N^{*} L C E s ;$ the $\lambda_{\text {peak }}$ values were $493 \mathrm{~nm}$ (E-A6), $501 \mathrm{~nm}$ (E-A10), and $539 \mathrm{~nm}$ (E-RM82). As mentioned previously, the $\lambda_{\text {peak }}$ 
of $\mathrm{N}^{*}$ LCEs changes when mesogenic crosslinkers are used instead of methylene chains. According to the general knowledge of chiral transfer from chiral agents to achiral nematic LCs, the HTP of a chiral agent, as well as $\lambda_{\text {peak }}$, should not change significantly with different crosslinkers [41,42]. However, the $\mathrm{N}^{*}$ LCEs exhibited different $\lambda_{\text {peak }}$ at the initial state, and the $\mathrm{N}^{*} \mathrm{LCE}$ with a mesogenic crosslinker (E-RM82) had a larger value (Figure 3b). To investigate the relationship between the chemical systems with mesogenic crosslinkers and the HTP of a chiral agent, we evaluated HTP by using HTP $=(P \cdot c)^{-1}$ and $\lambda_{\text {peak }}=n_{\text {ave }} \cdot P$, where $n_{\text {ave }}$ was assumed to be 1.6 [43-45]. As a result, the HTP values of the $\mathrm{N}^{*} \mathrm{LCEs}$ were $10.8 \mu^{-1}$ (E-A6), $10.6 \mu \mathrm{m}^{-1}$ (E-A10), and $9.89 \mu \mathrm{m}^{-1}$ (E-RM82). We assumed that the slight decrease in HTP which occurred only in the $\mathrm{N}^{*} \mathrm{LCE}$ with a mesogenic crosslinker (E-RM82) was due to the difference in the total molar ratio of the mesogenic compounds. Thus, we recalculated the HTP in the system of E-RM82 by using the molar ratio of chiral agent $(=28 \mathrm{~mol} \%)$ to the total mass of mesogenic compounds, which is the sum of concentrations of $\mathrm{HAB}, 5 \mathrm{CB}$, and RM82. As a result, the recalculated HTP in the system of E-RM82 becomes $10.6 \mu \mathrm{m}^{-1}$.

(a)

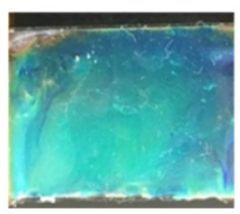

E-A6

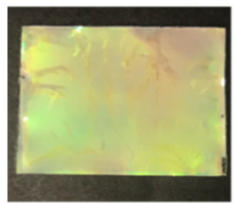

E-RM82 (b)

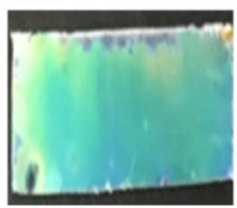

E-A10

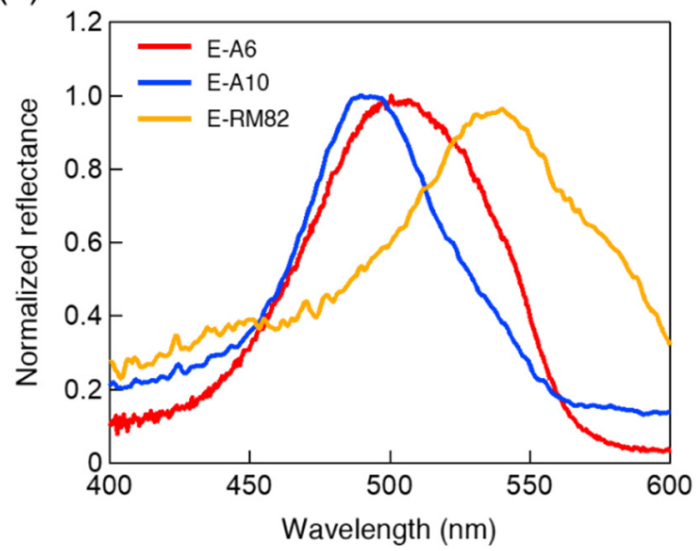

Figure 3. (a) Photographs and (b) normalized reflectance spectra of E-A6, E-A10, and E-RM82.

To further investigate this assumption, we prepared another $\mathrm{N}^{*} \mathrm{LCE}$, referred to as E-HFA, with a mesogenic crosslinker, where the molar ratio of the chiral agent to the total amount of mesogenic compounds was set as $30 \mathrm{~mol} \%$ (Table 2). As shown in Figure $4 \mathrm{a}$, E-HFA had a bluish-green appearance, similar to E-A6 and E-A10. Furthermore, the $\lambda_{\text {peak }}$ of E-HFA was $507 \mathrm{~nm}$ (Figure 4b), similar to that of E-A6 and E-A10. These results suggest that HTP is related to the molar ratio of not only a chiral agent in the chemical system, but also mesogenic compounds. This provides a strategy for designing mechano-optical sensors with the desired initial reflection color by adding certain amounts of chiral agents, irrespective of the crosslinker.

Table 2. Molar ratios of the compounds used to synthesize E-RM82 and E-HFA.

\begin{tabular}{cccccc}
\hline \multirow{2}{*}{ N*LCE } & Monomer & Chiral Agent & Plasticizer & Crosslinker & Photoinitiator \\
\cline { 2 - 6 } & HAB & CHA & 5CB & RM82 & Irgacure651 \\
\hline E-RM82 & 50 & 30 & 20 & 7.0 & 1.0 \\
\hline E-HFA & 45 & 30 & 18 & 6.4 & 1.0 \\
\hline
\end{tabular}


(a)

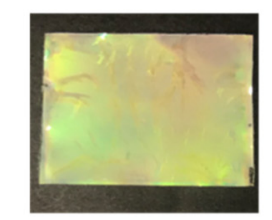

E-RM82

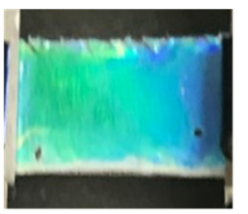

E-HFA (b)

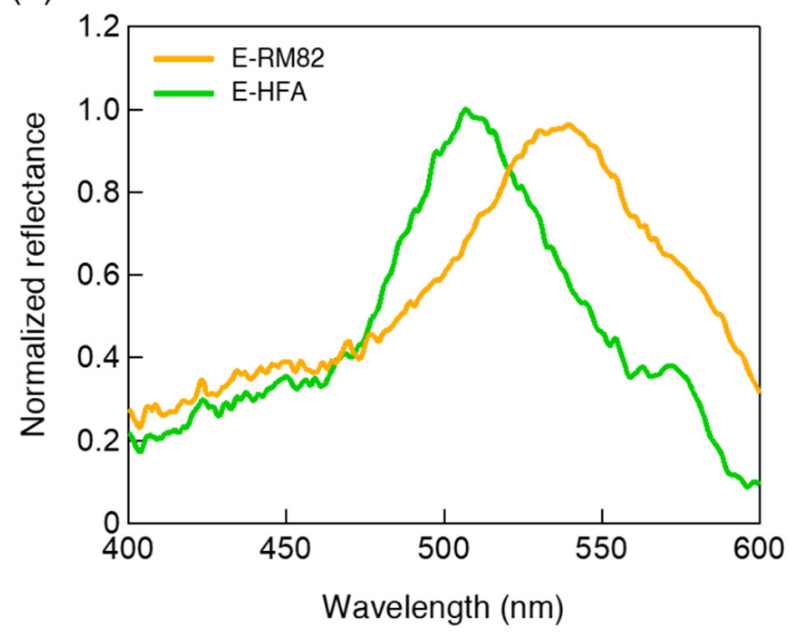

Figure 4. (a) Photographs and (b) normalized reflectance spectra of E-RM82 and E-HFA.

\subsection{Mechano-Optical Properties}

We investigated the mechano-optical properties of $\mathrm{N}^{*} \mathrm{LCEs}$ by reflection spectroscopy using a UV-vis spectrometer, where the incident light is delivered through an optical fiber and is normally irradiated to the film. The reflected light was detected by a photodiode array detector at the same angle. As representative examples, we investigated the effect of crosslinkers on the mechano-optical properties using E-A6 and E-RM82. Figure 5a compares the reflectance spectra of E-A6 and E-RM82 under no strain and 45\% strain. Elongation of both samples to $45 \%$ strain resulted in a blue-shift of the $\lambda_{\text {peak }}$, irrespective of the initial color (to $431 \mathrm{~nm}$ for E-A6 and to $484 \mathrm{~nm}$ for E-RM82). Considering Bragg's reflection formula with normal incident light, the change in the helical pitch can be expressed as follows: $\Delta \lambda_{\text {peak }}=n_{\text {ave }} \cdot \Delta P$. By transforming the formula, we evaluated the rate of change of the helical pitch: $\Delta \lambda_{\text {peak }} / \lambda_{\text {peak }}=\Delta P / P$, giving values of $14 \%$ and $13 \%$ for E-A6 and E-RM 82 , respectively. This indicates that the presented $\mathrm{N}^{*} \mathrm{LCEs}$ exhibit the same mechano-optical behavior, even with different crosslinkers. Typical LCEs exhibit different deformation behaviors depending on the chemical structure of the crosslinker. In our system, $N^{*}$ LCEs can be regarded as a gel swelled by a low-molecular-weight LC; thus, the deformation behavior is similar to that of the non-crosslinked system, and the effect of crosslinkers on molecular reorientation behavior is negligible.

(a)

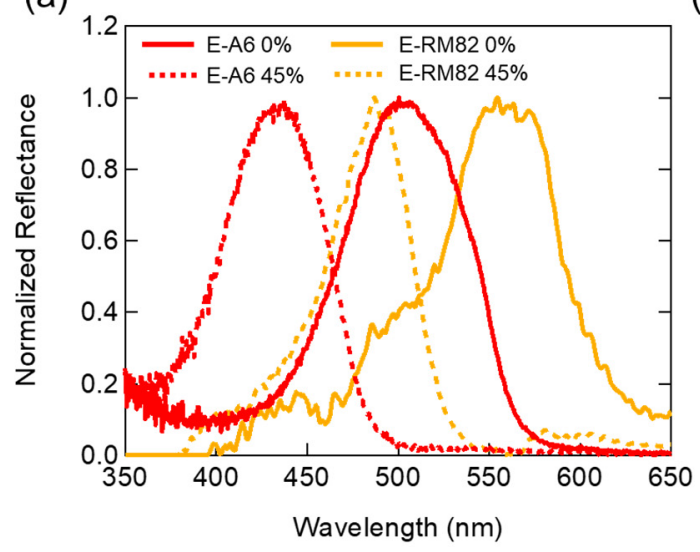

(b)

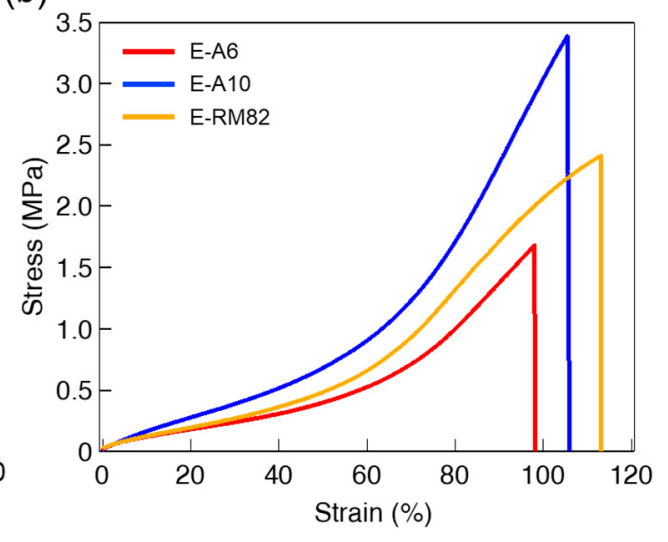

Figure 5. (a) Reflectance spectra of E-A6 and E-RM82 under tensile strain of $0 \%$ (solid line) and $45 \%$ (dashed line). (b) Stress-strain curves of the N*LCEs of E-A6, E-A10, and E-RM82. The strain was varied at a rate of $2 \mathrm{~mm} \mathrm{~min}^{-1}$. 
To further understand the effect of crosslinkers on the mechanical deformation behavior of $N^{*}$ LCEs, we conducted a tensile test, as shown in Figure 5b. The Young's modulus and breaking strain of each film were 2.1 MPa and 98\% strain (E-A6), 2.0 MPa and 105\% strain (E-A10), and 2.7 MPa and 113\% strain (E-RM82), respectively. The methylene chain length of the crosslinkers had no effect on the Young's modulus, but the ${ }^{*}$ LCE with a mesogenic crosslinker had higher stiffness. This can be explained by considering that aromatic $\pi$-conjugation has a stronger interaction than the methylene chains, which increases mechanical stiffness [46]. In addition, longer methylene chains in the crosslinker increased the breaking strain. This is reasonable because the $\mathrm{N}^{*}$ LCEs have the same crosslinking density but different methylene chain lengths, in which the $\mathrm{N}^{*} \mathrm{LCEs}$ with longer methylene chain lengths deform over a wider range. These results provide the effect of a crosslinker in the mechano-optical actuation of $\mathrm{N}^{*} \mathrm{LCE}$, indicating that mechanical properties such as stiffness and stretchability can be independently controlled by using a different crosslinker. Moreover, this strategy can be used to design a mechano-optical sensor that satisfies the mechanical requirements of practical applications.

\section{Materials and Methods}

\subsection{Materials}

The chemical structures of the materials used to prepare the $\mathrm{N}^{*} \mathrm{LCEs}$ are shown in Scheme 1. A LC monomer (HAB) and a mesogenic crosslinker (RM82) were supplied by Osaka Organic Chemical Ind. Ltd. (Osaka, Japan) and were used after recrystallization from methanol. Non-mesogenic crosslinkers (A6 and A10) were purchased from a commercial supplier and used after purification by silica gel column chromatography using dichloromethane. A low-molecular weight LC (5CB) and a photoinitiator (Irgacure 651) were purchased from commercial suppliers and used as received. A chiral agent (CHA) was synthesized and purified as described previously [28,47]. The polydimethylsiloxane film (removal layer) was prepared as previously reported [27].

\subsection{Synthesis of $\mathrm{CHA}$}

6-(carboxyoxy)hexyl acrylate $(1.0 \mathrm{~g}, 6.0 \mathrm{mmol})$ and pyridine $(0.47 \mathrm{~g}, 6.0 \mathrm{mmol})$ were added to dry dicholro methane $\left(\mathrm{CH}_{2} \mathrm{Cl}_{2}, 50 \mathrm{~mL}\right)$ and stirred for $5 \mathrm{~min}$ at $0{ }^{\circ} \mathrm{C}$. Cholesteryl chloroformate $(2.7 \mathrm{~g}, 6.0 \mathrm{mmol})$ was added to the mixture and stirred for $19 \mathrm{~h}$ at r.t. $\mathrm{CH}_{2} \mathrm{Cl}_{2}$ was then added to the reaction mixture and washed with distilled water and a saturated sodium chloride $(\mathrm{NaCl})$ aqueous solution. The organic layer was dried with anhydrous sodium sulfate $\left(\mathrm{Na}_{2} \mathrm{SO}_{4}\right)$. The crude product obtained was purified by silica gel column chromatography $\left(\mathrm{CH}_{2} \mathrm{Cl}_{2}\right)$ and recrystallization (methanol) to obtain $\mathrm{CHA}$. Yield: $48 \%$ as needle-like crystal ${ }^{1} \mathrm{H}$ NMR $\left(400 \mathrm{MHz}, \mathrm{CDCl}_{3}, \delta\right): 6.39(\mathrm{dd}, J=17.3,1.5 \mathrm{~Hz}$; $1 \mathrm{H} ; \mathrm{CH} H=\mathrm{CH}), 6.10\left(\mathrm{dd}, J=17.3,10.3 \mathrm{~Hz} ; 1 \mathrm{H} ; \mathrm{CH}_{2}=\mathrm{CH}\right), 5.81(\mathrm{dd}, J=10.3,1.5 \mathrm{~Hz} ; 1 \mathrm{H}$; $\mathrm{CHH}=\mathrm{CH}), 5.38(\mathrm{~d}, J=5.2 \mathrm{~Hz} ; 1 \mathrm{H}$; in steroid), 4.49-4.41 (m, 1H; in steroid), 4.15-4.04 $\left(\mathrm{m}, 4 \mathrm{H} ; \mathrm{CH}_{2}=\mathrm{CHCOOCH}_{2}\left(\mathrm{CH}_{2}\right)_{4} \mathrm{CH}_{2}\right), 2.42-2.32$ (m, 2H; in steroid), 2.01-1.76 (m, 5H; $\mathrm{CH}_{2}=\mathrm{CHCOOCH} \mathrm{CH}_{2}\left(\mathrm{CH}_{2}\right)_{2} \mathrm{CH}_{2} \mathrm{CH}_{2}$ and steroid), $1.68-1.58$ (m, 5H; in steroid), $1.57-0.80$ $\left(\mathrm{m}, 36 \mathrm{H} ; \mathrm{CH}_{2}=\mathrm{CHCOO}\left(\mathrm{CH}_{2}\right)_{2}\left(\mathrm{CH}_{2}\right)_{2}\left(\mathrm{CH}_{2}\right)_{2}\right)$ and steroid), and 0.65 (s, 3H; in steroid). ${ }^{13} \mathrm{C}$ $\mathrm{NMR}\left(100 \mathrm{MHz}, \mathrm{CDCl}_{3}, \delta\right):$ 166.42, 154.73, 139.46, 130.71, 128.63, 123.02, 77.78, 67.71, 64.56, $56.75,56.18,50.05,42.38,39.78,39.60,38.12,36.93,36.62,36.25,35.88,31.98,31.90,28.67$, 28.58, 28.32, 28.11, 27.78, 25.72, 25.55, 25.36, 23.90, 22.94, 22.67, 21.12, 19.36, 18.80, and 11.95. MS (ESI+) $m / z[\mathrm{M}+\mathrm{Na}]^{+}$calcd. for $\mathrm{C}_{37} \mathrm{H}_{60} \mathrm{NaO}_{5}$ 607.4333; found 607.4352. Anal. Calcd. for $\mathrm{C}_{37} \mathrm{H}_{60} \mathrm{O}_{5}$ : C, 75.98; H, 10.34; O, 13.68. Found: $\mathrm{C}, 75.81 ; \mathrm{H}, 10.71 ; \mathrm{N}, 0.14$.

\subsection{Preparation of Polydimethylsiloxane Films}

Glass plates $\left(70 \times 50 \mathrm{~mm}^{2}\right)$ were dipped in a bath of $2.0 \mathrm{~g} \mathrm{~L}^{-1}$ ethanol solution of octadecyltriethoxysilane for $30 \mathrm{~min}$ at $60^{\circ} \mathrm{C}$. After the glass plates were heated at $120^{\circ} \mathrm{C}$ for $2 \mathrm{~h}$, a pair of glass plates was assembled to prepare polymerization cells, where the gap between the glass plates was adjusted to $110 \mu \mathrm{m}$ with Kapton ${ }^{\circledR}$-tape spacers. The precursor of polydimethylsiloxane elastomer with $10 \mathrm{wt} \%$ of a curing agent (Dow Corning Toray, 
Sylgard 184) was injected into the cell at room temperature. After the cell was cured at $75^{\circ} \mathrm{C}$ for $3 \mathrm{~h}$, a polydimethylsiloxane film with $110 \mu \mathrm{m}$ thickness was removed from the cell.

\subsection{Preparation of $N^{*} L C E S$}

Three types of $\mathrm{N}^{*} \mathrm{LCEs}$ were prepared using different crosslinkers. To prepare the monomer mixtures, HAB, CHA, 5CB (as a plasticizer), Irgacure 651, and the crosslinker were dissolved in tetrahydrofuran (THF); the solvent was then removed completely under reduced pressure. The molar ratios of the compounds in the monomer mixtures are summarized in Table 3. The sum of LC monomers and plasticizer was set to $100 \mathrm{~mol} \%$, and $7 \mathrm{~mol} \%$ of crosslinker and $1 \mathrm{~mol} \%$ of photoinitiator were used to prepare the $\mathrm{N}^{*} \mathrm{LCE}$. The synthesis procedure for the $\mathrm{N}^{*} \mathrm{LCEs}$ is schematically illustrated in Figure 6. A polydimethylsiloxane film (removal layer, $20 \times 25 \mathrm{~mm}^{2}$, and $110 \mu \mathrm{m}$ thickness) and Kapton ${ }^{\circledR}$-tape spacers (110 or $165 \mu \mathrm{m}$ thickness) and were adhered to a glass plate $\left(25 \times 25 \mathrm{~mm}^{2}\right)$. A pair of these glass plates was then assembled to give a polymerization cell with a $55 \mu \mathrm{m}$ gap between the removal layers. The monomer mixture was injected into the gap by capillary force at $80^{\circ} \mathrm{C}$ (isotropic temperature of the mixture) in the dark, and then the cell was cooled to $25^{\circ} \mathrm{C}$ ( $\mathrm{N}^{*} \mathrm{LC}$ phase temperature of the mixture). A shearing force was applied parallel to the injection direction of the LC mixture to induce homogeneous alignment of the helical molecular orientation in the $\mathrm{N}^{*} \mathrm{LC}$ phase. The mixture was photopolymerized by irradiation with a UV light-emitting diode (Iwasaki Electric Co. (Tokyo, Japan), LHPUV365; 365 nm; 5.0 $\left.\mathrm{mW} / \mathrm{cm}^{2}\right)$ for $5 \mathrm{~min}$ at $25^{\circ} \mathrm{C}$. Finally, $\mathrm{N}^{*} \mathrm{LCEs}\left(20 \times 25 \mathrm{~mm}^{2}\right.$ and $55 \mu \mathrm{m}$ thickness $)$ were peeled off the glass cell.

Table 3. Molar ratio of the compounds in the monomer mixtures used to prepare the $\mathrm{N}^{*} \mathrm{LCEs}$.

\begin{tabular}{cccccccc}
\hline \multirow{2}{*}{$\mathbf{N}^{*}$ LCE } & Monomer & Chiral Agent & Plasticizer & & Crosslinker & \multicolumn{2}{c}{ Photoinitiator } \\
\cline { 2 - 7 } & HAB & CHA & 5CB & A6 & A10 & RM82 & Irgacure 651 \\
\hline E-A6 & 50 & 30 & 20 & 7.0 & - & - & 1.0 \\
E-A10 & 50 & 30 & 20 & - & 7.0 & 7.0 & 1.0 \\
E-RM82 & 50 & 30 & 20 & - & - & 1.0 \\
\hline
\end{tabular}

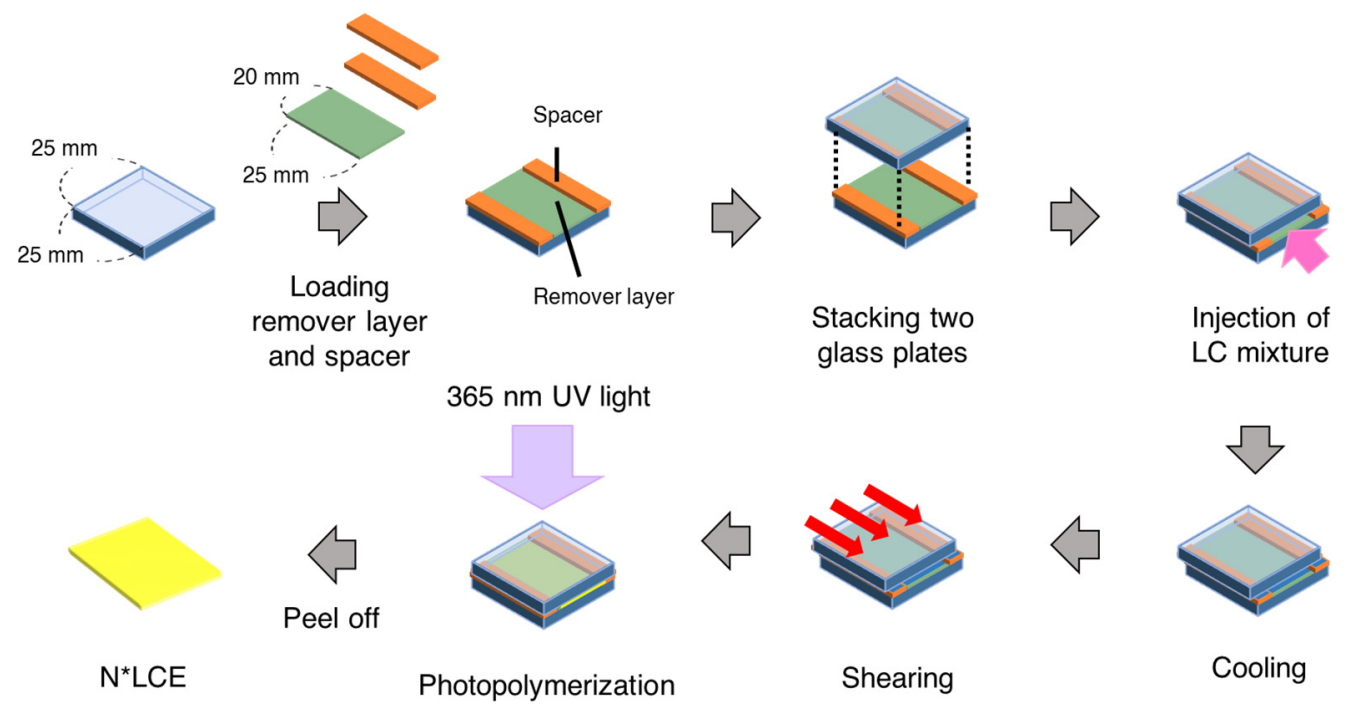

Figure 6. Schematic of the fabrication process for synthesizing $\mathrm{N}^{*} \mathrm{LCEs}$. 


\subsection{Characterization}

Nuclear magnetic resonance (NMR) spectroscopy was performed on a spectrometer (JEOL (Tokyo, Japan), ECS400; $400 \mathrm{MHz}$ for H-NMR, $100 \mathrm{MHz}$ for C-NMR) in the NMR solvent as an internal reference. Mass spectroscopy measurements were recorded by electrospray ionization (ESI) technique using a Bruker MICROTOF II (Billerica, MA, USA) and elemental analysis was measured using a MICRO CORDER JM10 (J-SCIENCE, Tokyo, Japan), respectively. The thermodynamic properties of the $\mathrm{N}^{*} \mathrm{LCEs}$ were analyzed using DSC (X-DSC7000, SEIKO Instruments, Chiba, Japan). DSC scans were performed within $-10 \sim 120{ }^{\circ} \mathrm{C}$ at a scanning rate of $10{ }^{\circ} \mathrm{C} \mathrm{min}^{-1}$ under nitrogen. The phase sequences and phase transition behaviors were determined using a POM instrument (Olympus, Tokyo, Japan, EX51TH) equipped with a hot stage (Instec, Boulder, CO, USA, HCS302 hot stage, and mK1000 controller). The phase transition behavior and DSC measurement were repeated for 3 cycles and the same results investigated regardless of cycle. The reflectance spectra were recorded using a UV-vis diode-array spectrometer (BLUE-WaveUVN, Stellar Net, Tampa, FL, USA) at room temperature at a tensile strain of $0 \%$ and $45 \%$ using digital venire calipers. Stress-strain curves were recorded using a tensile tester (Instron 5943, Instron) at room temperature with a strain rate of $2 \mathrm{~mm} \mathrm{~min}^{-1}$. Three specimens were prepared for evaluating the Young's modulus of $\mathrm{N}^{*} \mathrm{LCEs}$ and the values were averaged. The Young's modulus of the $\mathrm{N}^{*} \mathrm{LCEs}$ was determined from the slope of the stress-strain curve in the linear elastic range of $0.25-1.0 \%$. The test specimens of the $\mathrm{N}^{*} \mathrm{LCEs}$ with the size of $20 \times 5 \mathrm{~mm}^{2} \times 55 \mu \mathrm{m}$ were prepared by manually cutting the bare $N^{*}$ LCEs with the size of $20 \times 25 \mathrm{~mm}^{2} \times 55 \mu \mathrm{m}$.

\section{Conclusions}

To investigate the effect of the crosslinking units in a $\mathrm{N}^{*} \mathrm{LCE}$ network, $\mathrm{N}^{*} \mathrm{LCEs}$ were synthesized with various crosslinkers, and the phase transition behavior as well as thermal, optical, and mechanical properties were investigated. The $\mathrm{N}^{*} \mathrm{LCEs}$ exhibited a bright color due to selective reflection and a reversible thermal phase transition. Long methylene chain units on the crosslinker increased the $T_{\mathrm{g}}$ and $T_{\mathrm{c}}$ of the $\mathrm{N}^{*}$ LCEs. The LC-type crosslinker contributed to stabilizing the $\mathrm{N}^{*} \mathrm{LC}$ phase by increasing molecular order and rigidity. The LC-type crosslinker decreased the HTP of $\mathrm{N}^{*}$ LCEs by increasing the molar ratio of the mesogenic compounds. The $\mathrm{N}^{*} \mathrm{LCEs}$ showed the same optical shift trend by mechanical deformation despite the presence of different types of crosslinker, accompanied by variations in the magnitude of the blue-shift in the reflectance. Moreover, the mechanical properties of $\mathrm{N}^{*} \mathrm{LCE}$ can be controlled using crosslinkers. These findings provide guidelines for the synthesis of improved $N^{*} \mathrm{LCE}$ materials with enhanced performance as stimuli-responsive materials.

Author Contributions: Conceptualization, O.T.; investigation, K.K., K.H., T.S., K.Y., N.A., and A.S.; formal analysis, K.K., K.H., and K.Y.; writing — original draft preparation, K.K., and K.H.; writingreview and editing, K.H., T.S., and O.T. All authors have read and agreed to the published version of the manuscript.

Funding: This research was supported by the Japan-India Science Cooperative Program between JSPS and DST (JPJSBP120217715), JSPS KAKENHI (20K15249 for KH), and the Cooperative Research Program of the Network Joint Research Centre for Materials and Devices (Tokyo Institute of Technology).

Institutional Review Board Statement: Not applicable.

Informed Consent Statement: Not applicable.

Data Availability Statement: The authors confirm that the data supporting the findings of this study are available within the article.

Acknowledgments: We thank Osaka Organic Chemical Industry for providing the liquid crystal monomers and crosslinkers. 
Conflicts of Interest: The authors declare no conflict of interest.

Sample Availability: Samples of the compounds are not available from the authors.

\section{References}

1. Ryabchun, A.; Bobrovsky, A. Cholesteric liquid crystal materials for tunable diffractive optics. Adv. Opt. Mater. 2018, 6, 1800335. [CrossRef]

2. White, T.J.; McConney, M.E.; Bunning, T.J. Dynamic color in stimuli-responsive cholesteric liquid crystals. J. Mater. Chem. 2010, 20, 9832-9847. [CrossRef]

3. Guo, J.; Wu, H.; Chen, F.; Zhang, L.; He, W.; Yang, H.; Wei, J. Fabrication of multi-pitched photonic structure in cholesteric liquid crystals based on a polymer template with helical structure. J. Mater. Chem. 2010, 20, 4094-4102. [CrossRef]

4. Tokunaga, S.; Itoh, Y.; Tanaka, H.; Araoka, F.; Aida, T. Redox-responsive chiral dopant for quick electrochemical color modulation of cholesteric liquid crystal. J. Am. Chem. Soc. 2018, 140, 10946-10949. [CrossRef] [PubMed]

5. $\quad$ Lin, J.D.; Lin, H.Y.; Wei, G.J.; Chuang, Y.C.; Chen, L.J.; Mo, T.S.; Lee, C.R. A broadban-tunable photonic bandgap and thermally convertible laser with an ultra-low lasing threshold from a refilled chiral polymer template. J. Mater. Chem. C 2019, 7, $4740-4747$. [CrossRef]

6. Mulder, D.J.; Schenning, A.P.H.J.; Bastiaansen, C.W.M. Chiral-nematic liquid crystals as one dimensional photonic materials in optical sensors. J. Mater. Chem. C 2014, 2, 6695-6705. [CrossRef]

7. Fu, P.; Ye, P.; Yu, Z.; Lu, H. Bragg reflection from a cholesteric liquid-crystal slab in the framework of nonlinear optics. J. Opt. Soc. Am. B 1987, 4, 1392-1396. [CrossRef]

8. Bian, Z.; Li, K.; Huang, W.; Cao, H.; Yang, H. Characteristics of selective reflection of chiral nematic liquid crystalline gels with a nonuniform pitch distribution. Appl. Phys. Lett. 2007, 91, 201908. [CrossRef]

9. Hu, W.; Zhang, L.; Cao, H.; Song, L.; Zhao, H.; Yang, Z.; Cheng, Z.; Yang, H.; Guo, L. Electro-optical study of chiral nematic liquid crystal/chiral ionic liquid composites with electrically controllable selective reflection characteristics. Phys. Chem. Chem. Phys. 2010, 12, 2632-2638. [CrossRef]

10. Humar, M.; Muševič, I. 3D microlasers from self-assembled cholesteric liquid-crystal microdroplets. Opt. Express 2010, 18, 26995-27003. [CrossRef]

11. Schwartz, M.; Lenzini, G.; Geng, Y.; Rønne, P.B.; Ryan, P.Y.A.; Lagerwall, J.P.F. Cholesteric liquid crystal shells as enabling material for information-rich design and architecture. Adv. Mater. 2018, 30, 1707382. [CrossRef] [PubMed]

12. John, W.D.S.; Fritz, W.J.; Lu, Z.J.; Yang, D.K. Bragg reflection from cholesteric liquid crystals. Phys. Rev. E 1995, 51, 1191. [CrossRef] [PubMed]

13. Kahn, F.J. Cholesteric liquid crystals for optical applications. Appl. Phys. Lett. 1971, 18, 231. [CrossRef]

14. Picot, O.T.; Dai, M.; Billoti, E.; Broer, D.J.; Peijs, T.; Bastiaansen, C.W.M. A real time optical strain sensor based on a cholesteric liquid crystal network. RSC Adv. 2013, 3, 18794-18798. [CrossRef]

15. Foelen, Y.; Van Der Heijden, D.A.C.; del Pozo, M.; Lub, J.; Bastiaansen, C.W.M.; Schenning, A.P.H.J. An optical steam sterilization sensor based on a dual-responsive supramolecular cross-linked photonic polymer. ACS Appl. Mater. Interfaces 2020, 12, 1689616902. [CrossRef]

16. Zhang, B.Y.; Hu, J.S.; Wang, Y.; Qian, J.H. Synthesis and properties of side-chain cholesteric liquid crystalline elastomers containing tetra-vinyl crosslinking units. Polym. J. 2003, 35, 476-483. [CrossRef]

17. Khandelwal, H.; Timmermans, G.H.; Debije, M.G.; Schenning, A.P.H.J. Dual electrically and thermally responsive broadband reflectors based on polymer network stabilized chiral nematic liquid crystals: The role of crosslink density. Chem. Commun. 2016, 52, 10109-10112. [CrossRef]

18. Varanytsia, A.; Nagai, H.; Urayama, K.; Palffy-Muhoray, P. Tunable lasing in cholesteric liquid crystal elastomers with accurate measurements of strain. Sci. Rep. 2015, 5, 17739. [CrossRef]

19. Yusuf, Y.; Ono, Y.; Sumisaki, Y.; Cladis, P.E.; Brand, H.R.; Finkelmann, H.; Kai, S. Swelling dynamics of liquid crystal elastomers swollen with low molecular weight liquid crystals. Phys. Rev. E 2004, 69, 021710. [CrossRef]

20. Meng, F.B.; Lian, J.; Chen, H.B.; Gao, Y.M.; Zhang, B.Y. Cholesteric liquid-crystalline thermosets derived from side-chain liquid-crystalline epoxy oligomers. High Perform. Polym. 2008, 21, 64-78.

21. Hu, J.S.; Zhang, B.Y.; Yao, D.S.; Zhou, A.J. Cholesteric liquid crystalline thermosets: Synthesis, structure and properties of ChLCTs/precursor polymers. Liq. Cryst. 2004, 31, 393-400. [CrossRef]

22. Mamiya, J. Photomechanical energy conversion based on cross-linked liquid-crystalline polymers. Polym. J. 2013, 45, 239-246. [CrossRef]

23. Jiang, H.; Li, C.; Huanga, X. Actuators based on liquid crystalline elastomer materials. Nanoscale 2013, 5, 5225-5240. [CrossRef]

24. Fuchigami, Y.; Takigawa, T.; Urayama, K. Electrical actuation of cholesteric liquid crystal gels. ACS Macro Lett. 2014, 3, 813-818. [CrossRef]

25. Nagai, H.; Urayama, K. Thermal response of cholesteric liquid crystal elastomers. Phys. Rev. E 2015, 92, 022501. [CrossRef] [PubMed]

26. Finkelmann, H.; Kim, S.T.; Muñoz, A.; Palffy-Muhoray, P.; Taheri, B. Tunable mirrorless lasing in cholesteric liquid crystalline elastomers. Adv. Mater. 2001, 13, 1069-1072. [CrossRef] 
27. Ku, K.; Hisano, K.; Kimura, S.; Shigeyama, T.; Akamatsu, N.; Shishido, A.; Tsutsumi, O. Environmentally stable chiral-nematic liquid-crystal elastomers with mechano-optical properties. Appl. Sci. 2021, 11, 5037. [CrossRef]

28. Ku, K.; Kimura, S.; Yuasa, K.; Hisano, K.; Tsutsumi, O. Control of molecular-level mechano-optical response of chiral liquidcrystalline elastomers. Proc. SPIE 2020, 11477, 1147703.

29. Liu, Z.P.; He, X.Z.; Cong, Y.H.; Zhang, B.Y.; Meng, F.B.; Tian, M.; Jia, Y.G. Synthesis and characterization of two series of pressure-sensitive cholesteric liquid crystal elastomers with optical properties. Liq. Cryst. 2020, 47, 143-153. [CrossRef]

30. Jiang, Y.; Cong, Y.; Zhang, B. Synthesis and characterization of chiral smectic side-chain liquid crystalline elastomers containing nematic and chiral mesogens. New J. Chem. 2016, 40, 9352-9360. [CrossRef]

31. Zhang, Y.S.; Jiang, S.A.; Lin, J.D.; Lee, C.R. Bio-inspired design of active photo-mechano-chemically dual-responsive photonic film based on cholesteric liquid crystal elastomers. J. Mater. Chem. C 2020, 8, 5517-5524. [CrossRef]

32. Hu, J.S.; Zhang, B.Y.; Sun, K.; Li, Q.Y. Side chain cholesteric liquid crystalline elastomers: Synthesis and phase behaviour. Liq. Cryst. 2003, 30, 1267-1275. [CrossRef]

33. Ma, Y.R.; Wang, D.X.; Cong, Y.H.; He, X.Z.; Zhang, B.Y.; Meng, F.B.; Jia, Y.G. Synthesis and properties of cholesteric liquid crystal elastomers with selective reflection centred on $\mathrm{D}(+)$-camphoric acid. Liq. Cryst. 2020, 47, 1591-1603. [CrossRef]

34. Zhang, B.Y.; Hu, J.S.; Jia, Y.G.; Du, B.G. Side-chain cholesteric liquid crystalline elastomers derived from nematic bis-olefinic crosslinking units. Macromol. Chem. Phys. 2003, 204, 2123-2129. [CrossRef]

35. He, X.Z.; Zhang, B.Y.; Ma, W.W.; Zhang, L.; Mu, Q. Side-chain cholesteric liquid crystalline elastomers containing isosorbide as chiral agent-Synthesis and characterization. Liq. Cryst. 2009, 36, 847-854. [CrossRef]

36. Thomas, R.; Yoshida, Y.; Akasaka, T.; Tamaoki, N. Influence of a change in helical twisting power of photoresponsive chiral dopants on rotational manipulation of micro-objects on the surface of chiral nematic liquid crystalline films. Chem. Eur. J. 2012, 18, 12337-12348. [CrossRef]

37. Baessler, H.; Labes, M.M. Helical twisting power of steroidal solutes in cholesteric mesophases. J. Chem. Phys. 1970, 52, 631. [CrossRef]

38. Sánchez-Ferrer, A.; Torras, N.; Esteve, J. Integration of liquid-crystalline elastomers in MEMS/MOEMS. In Liquid Crystalline Polymers, 1st ed.; Thakur, V.K., Kessler, M.R., Eds.; Springer: Cham, Switzerland, 2016; Volume 1, pp. 553-582.

39. Jirón, V.; Castellón, E. Increased nematic-isotropic transition temperature on doping a liquid crystal with molecularly rigid carboxylic acids. J. Phys. Chem. B 2020, 124, 890-899. [CrossRef]

40. Huang, C.; Qian, X.; Yang, R. Thermal conductivity of polymers and polymer nanocomposites. Mater. Sci. Eng. R Rep. 2018, 132, 1-22. [CrossRef]

41. Wu, X.; Cao, H.; Guo, R.; Li, K.; Wang, F.; Yang, H. Effect of cholesteric liquid crystalline elastomer with binaphthalene crosslinkings on thermal and optical properties of a liquid crystal that show smectic A-cholesteric phase transition. Polym. Adv. Technol. 2013, 24, 228-235. [CrossRef]

42. McConney, M.E.; White, T.J.; Tondiglia, V.P.; Natarajan, L.V.; Yang, D.; Bunning, T.J. Dynamic high contrast reflective coloration from responsive polymer/cholesteric liquid crystal architecture. Soft Matter 2012, 8, 318-323. [CrossRef]

43. Pan, R.P.; Tsai, T.R.; Chen, C.Y.; Wang, C.H.; Pan, C.L. The refractive indices of nematic liquid crystal 4'-n-pentyl-4-cyanobiphenyl in the THz frequency range. Mol. Cryst. Liq. Cryst. 2004, 409, 137-144. [CrossRef]

44. Li, Y.; Luo, D.; Peng, Z.H. Full-color reflective display based on narrow bandwidth templated cholesteric liquid crystal film. Opt. Mater. Express 2017, 7, 16-24. [CrossRef]

45. Gharde, R.; Bhave, M.G. The study of refractive indices of liquid crystal mixtures. Mol. Cryst. Liq. Cryst. 2015, 613, 1-15. [CrossRef]

46. Chen, Y.; Tan, L.; Chen, L.; Yang, Y.; Wang, X. Study on biodegradable aromatic/aliphatic copolyesters. Br. J. Chem. Eng. 2008, 25, 321-335. [CrossRef]

47. Albuquerque, H.M.T.; Santos, C.M.M.; Silva, A.M.S. Cholesterol-based compounds: Recent advances in synthesis and applications. Molecules 2019, 24, 116. [CrossRef] [PubMed] 